Third International Engineering Systems Symposium

CESUN 2012, Delft University of Technology, 18-20 June 2012

\title{
Capacities and governance in Kenya: lessons in technology transfer
}

\author{
Otto Kroesen $^{1}$, David Ndegwah ${ }^{2}$ \\ ${ }^{1}$ TPM, TU Delft, Department of Values, Jaffalaan 5, 2628 BX Delft, The Netherlands \\ ${ }^{2}$ Bondo University College, School of Education and Social Sciences, P. O. Box 210, Bondo, \\ Kenya \\ J.O.Kroesen@TUDelft.nl; NdegwahDavid@gmail.com
}

\begin{abstract}
.
First the authors set the scene by exploring the main lines of the present development debate. They take a nuanced stand, not only looking at failures of Western development initiatives, but also going into the internal dynamics of African societies which stand in the way of social and economic development. Next they present some case studies of entrepreneurial development initiatives from Kenya. These cases show the difficulties in terms of organization and capacities such initiatives have to deal with, and they also take into consideration the bigger picture in terms of sector development, regulation, and finally civil society and governance issues. Kenya is caught up between a value set of traditional values adapted to small scale ethnic societies, which doesn't exercise its cohesive function like it once did anymore, and modern large-scale and open civil society values, which are not yet fully in place. It is the contention of the authors, that progress is to be made by means of a mutually reinforcing combination of entrepreneurial skills and capacities, i.e. initiatives from below, and adequate institutionalization and regulation from above.
\end{abstract}

Keywords. Technology Transfer, Entrepreneurship, Cultural and Institutional Transition, Civil Society

\section{Introduction}

In 2007 the board of the TU Delft decided to give cooperation with and technology transfer to Africa a high priority on its agenda. Lustrum activities were devoted to Africa. Since that time especially within the framework of the minor 'International entrepreneurship and Development' many internships were completed in technology transfer, innovation and sustainable entrepreneurship in Africa. Besides that a number of master theses combined with entrepreneurial internships were completed.

This contribution especially focuses on Kenya, where an extensive internship program has been developed in cooperation with NGOs, entrepreneurs and universities, especially with teachers from Jomo Kenyatta University, Tangaza College and Bondo University College. Some case studies from Kenya will be reported and experiences, 
both in terms of obstacles and opportunities will be evaluated with a view on further steps to be taken. Before going into these case studies the reader will be introduced into the development debate and its different and competing positions in relation to sub-Saharan Africa and introduced into the sociocultural dynamics of the sub-Saharan countries in order to set the scene.

Both opportunities and obstacles have been discovered. Among the opportunities are the discovery of many relevant partners and initiatives, either enterpreneurial or from NGOs, vocational training and higher learning institutions. Among the barriers are the strong compartmentalization of the African society, insufficiently universalistic governance, a relatively weak civil society interaction, insufficient development of skills and capacities.

\section{The development debate focused on sub-Saharan Africa}

What is it in the African culture that stands in the way of modernization? We echo some voices from the debate without aiming at completeness. Jeffrey Sachs (2005) mentions the poverty trap as a self-perpetuating vicious circle; while Paul Collier (2007) adds other traps besides that, like the land lock trap (like being surrounded by badly functioning neighbours, without opening to the sea), the civil war trap (once a civil war has happened it is very difficult to build up the economy, because of lack of trust; which, in the end, leads to more civil wars), the natural resources trap (revenues from natural resources make it possible for autocratic leaderships to evade democratic elections). Easterly (2006) adds the Western habit of making big plans to the list, which mostly are designed to suit the western electorate ('We are doing something about it!') and show no accountability to the poor they claim to help. He further mentions insufficient professionalism with the donors, who want to be involved in everything and refuse to specialize and professionalize in anything. Ha-Joon Chang (2007) primarily criticizes neoliberal economic policies of the 'unholy trinity' of the IMF, the World Bank and the WTO, constantly calling for a 'level playing field' (Chang , 2007, 218) between unequal forces. In effect such neoliberal policies, following the ad hoc streams of capital, prevent developing countries from installing effective long-term industrial policies and building up productive capabilities.

Experts in development, however, are increasingly pointing the finger at the African actors, especially the leadership. Robert Calderisi mentions mismanagement of the political leadership, high production and distribution costs, a poor investment climate and lack of unified policies among African states (Calderisi, 2006). He criticizes the political correctness, due to colonial history and slavery, of the West, as giving 'a final touch to Africa's misery'. On his part, Roel van der Veen gives an insight into the tribulations that Africa has faced right from the time of the Cold War; the economic decline the continent went through, the many civil wars, of which some amounted to genocide (as it happened in Rwanda, in 1994) and finally the disintegration of some states: as witnessed in Somalia, twenty years after the overthrow of Mohamed Siad Barre (Van der Veen, 2004). He points out that the failure of Africa to develop can be blamed on internal as well as external factors, as most people have always done, but he insists that external factors are not the 
overriding cause. He has finally blamed this state of affairs on misappropriation of funds from the donors, selfishness and greed, among the leaders; all of which can be summed up in one word - corruption (Van der Veen, 2004, 356). Maybe one of the most radical solutions for development has been proposed by Dambisa Moyo by arguing that development aid as such should stop, especially government to government aid (Moyo, 2009). That, in her perspective, would force African governments to be more accountable to their populations.

Looking at the broader picture of development approaches Des Gasper (2004) gives an overview of five decades of development; he criticizes the emphasis on development in purely economic terms of the early years. Some large projects involved conscious sacrificing of the well-being of certain groups like indigenous peoples whose land and resources were taken from them. The structural adjustment programs of the World Bank often made things worse; because the concentration on the Gross Domestic Produce (GDP) growth does not say much about the distribution of welfare and general employment. The so-called efficient development aid is not helpful, either, because it often did not answer the question: 'efficient in what respect'? Efficiency also implies certain assumptions and beliefs concerning what can be considered as valuable and what cannot. He, therefore, welcomes the broadening of the ideas on development in the 90s; including matters of personal security and societal peace. This is because, to a large extent, the neoliberal so-called economic 'reforms' have set in motion a process of socio-political decay.

Where, during the 80s, comparative economics was in the driver's seat, in the 90s the many conflicts, in Africa and around the world, in developing countries, led to new views on development. People should at least be able to exercise their humanity. The rights-based approach and the capabilities approach entered the scene of the development debate. The capability approach makes us look at a set of life options that every person has, or should have. Des Gasper values the approach of Amartiya Sen, in the sense that he emphasizes positive freedoms and capacities to achieve things, which one has reason to value (Sen, 1999). Des Gasper also calls attention to the so-called 'significative values'. Only if people feel they need a meaningful life, do they find inspiration to work hard and disciplined. These 'significative values' give meaning to life and are often religious, in origin. And yet, he laments, 'Despite the pre-eminence of religions historically and still in the lives of vast numbers of people, development discourse has largely ignored them' (Des Gasper, 2004, 146). This brings us to the role of culture.

\section{Traditional African Values}

We would like to call for attention to the original unity of religious and social or cultural values; which, in the African context, are one and the same thing. Traditionally it was impossible to separate respect for the elders from belief in the authority of the ancestors, the first being a social value, while the second is a religious belief. We, however, see that this is not always the case any longer; in the name of being enlightened or developed (often put pejoratively - we are not backward!). And yet in the traditional African culture these two dovetail into each other, and are not 
separable. The word culture itself is derivative of another English word, "cult", signifying the religious origin of the so-called cultural values; as it does in other languages of the Western society too. For this reason, we would like to analyse the deeper meaning giving cultural layers and mindsets.

Calderisi gives a short survey of the African values, attributing the typical communal values of Africa to its harsh natural circumstances. Traditionally, he says, only harmonious groups, families and tribal relationships could help to surmount the obstacles thrown up by nature (Calderisi, 2006). In addition Africans live in the here and now and enjoy life as it is; which can lead to remarkable paradoxes. An international survey, in 2003, found that Nigeria, despite its dictatorship and corruption, had the highest percentage of happy people in the world. Authority is venerated; people do not easily speak out in a group, while a large group of uneducated Africans are fatalistic, and feel there is little they can do to control events. In general Africans are patient and endure long periods of suffering - a quality without which Africa could not have survived its tribulations, according to Calderisi.

Traditionally indeed, Africa, throughout history, has been mainly organized in tribal societies. An important question, at this juncture, is: how much of the old mentality of autocratic chiefs (ruling over 300 to 10,000 people) has gone into the mentality of modern dictatorial leaders like, Amin, Ngueso, Mobutu and Mugabe, among many others; now ruling over millions of people? This is, however, not to say that other parts of the world have not produced their share of bad leaders. The checks and balances of the old system are gone; and yet new ones are not in place. On the one hand, without modern technology, serving the centralized administration, such dictatorial political units would not have been possible. It is as if the autocratic rulership of the old chiefs is transplanted into a context of modern communication, transportation, and, not to forget, military technology. Originally the power of the chiefs was kept in check by the age group system, by which in general a closely knit together group of men of about the same age would come to power and devolve their office after about 15 years (Reader, 1997). At the high point of colonialism there were still no more than a thousand British civil servants administering the whole of Africa. They ruled by means of the chiefs they appointed, and beckoned at will by their military force. By this system colonialism reinforced the autocratic authority of the African chiefs, because the English administration used the chiefs as intermediaries (Easterly, 2006). However, the patriarchal community values, by which these chiefs ruled small political units turn into dictatorial control, if transplanted to bigger and modern political units. The devil - so to say - does not change the label if he changes the content of the bottle.

\section{Civil society and governance}

Although traditional values underwent such deformation institutional checks and balances, like a free press, independent judiciary, independent accountancy of expenditures, a strong civil society and so forth, are often not functioning. At the background of this scenario is the complex relationship between state and society (Wiarda, 2003, OSSREA, 2009, Kasfir, 1998). An open civil society can only 
function if a strong and yet accountable government enforces universalistic rules, so that particularistic mindsets and patronage systems cannot obstruct an open process of constantly regrouping of social actors (Popper, 1965, Fukuyama, 2011), which is indispensable for innovation. Gyekye (1997, 242-260, 287-297) sees development bottlenecks in Africa within cultural practices that do not help in building a modern society. These are: 1) a negative attitude towards science; 2) ethnicity over and above humanity; 3 ) apathy towards public service and 4) primacy of the community over the individual. For him, an emphasis on educational and training programs in science and technology can go a long way to help and turn round cultural attitudes. A substitution of the bottlenecks related to extreme communitarianism with a stronger focus on individual responsibility and equality could obtain a credible dialogue with modernity. Indeed, as Nyasani (2010, vii) observes, “...Africa which is hankering after the attainment of the Western model of development cannot actually achieve it without changing its reveterate habits and attitudes in the most radical and deliberate manner possible in tune with the West's development fervour, pace and rigour." Museveni (1996, 193-194) is even more pessimistic on the continent's economic survival: 'Societies that do not master science and technology will either be slaves, surviving at the mercy and sufferance of others, or will perish altogether.'

\section{Entrepreneurial activities and their context}

For a long time the development debate has been dominated by a community approach. Local communities were to be organized to take responsibility for their development by means of participation and involvement in community-based programs and community committees (Schouten \& Moriarty, 2003). In recent years the emphasis shifted towards entrepreneurship, looking at the millions at the bottom of the pyramid as consumers and producers (Prahalad, 2002). Where Prahalad initially focused on large-scale enterprises producing cheap commodities for mass consumption in developing countries, others came in with the idea of bottom to bottom business ventures, putting more confidence in many small-scale initiatives, since markets at the bottom of the pyramid are difficult to penetrate by large scale one-size-fits-all entrepreneurial approaches. If productive capacities and business skills are lacking small enterprises which are thoroughly contextualized can have a bigger impact (Samli, 2009). As will be corroborated by the case material presented below, such small-scale initiatives need to be embedded in larger scale policies, visions and therefore innovation systems (Jakobsson and Bergek, 2006), and they also will have to take the cultural specificities into account in their management system and capacity development, including cross-cultural learning processes (Kroesen and Rozendaal, 2010).

\subsection{Solid waste management in Nairobi}

In Nairobi students from the Technical University Delft studied the business model of different solid waste recycling companies (Alberts e.a., 2010). It appears that a business in the recycling of solid waste has to operate in a challenging and complex 
environment. The Nairobi City Council (NCC) charges every area in Nairobi for waste collection. But NCC has not enough equipment itself to pick up all the waste. Since the 90s the quantity of waste increased, whereas the number of trucks to collect it decreased. There were 1000 tons of waste per day and 100 trucks in the 70 s and $80 \mathrm{~s}$, but in the $90 \mathrm{~s}$ the waste increased to 1600 tons per day and the number of trucks decreased to 40. During the research there was 2400 tons of waste per day. For that reason $80 \%$ of all the waste is picked up by either community-based organizations or small and medium enterprises.

Although there are a lot of laws and policies related to solid waste management, actually and effectively a broader policy framework is lacking. Targets are set for the amount of waste to be collected and the amount of trees and public gardens in Nairobi. Every quarter there is an evaluation of these targets and new targets are set for the next quarter. Besides that NCC has divided Nairobi into different zones for waste collection. Officially the collectors can only pick up waste in the zones that are assigned to them, but due to lack of rule enforcement in practice the collectors can collect wherever they want. Most collectors, especially the smaller ones, collect waste only in their neighborhood. Plastic is the most valuable product to be recycled. Occasionally it occurs that the competition has already picked up all the plastic and the collectors have to go to another place. A lot of areas in Nairobi are partially or completely not served by the NCC or any other collection company. Nevertheless competition in the solid waste sector is really stiff, exactly because it is not regulated at all. Illegal dumping is not prevented and not controlled by NCC, although it is one of the causes of unfair competition. Companies are sometimes afraid to invest also because of the uncertain future in view of the legislation on waste collection companies and truck requirements. Other complaints about NCC are that sometimes plastic recyclers have to pay a corruption fee, that NCC makes top-down decisions without consultation of collecting companies, which leads to legislation and statistics based on theory instead of practice and experience. There is no cooperation between the collection companies and the NCC.

After collecting the solid waste the companies start separating the plastic. Sometimes this is already done during transport. In order to add value plastics are sorted on color and type. Then it is washed in a big tank and cut to pieces by a machine and finally it is put in bags. It can be sold in a minimum amount of one and a half ton. At another project bones are also reused and toxic waste is dealt with by means of incinerators and the rest of the waste, which is useless, is dumped.

There are many companies working together with community-based organizations, which collect the waste and bring it to the collection place. Most of the companies also have a goal to help the community and create jobs. This is a reason for them to employ street boys. One of the biggest challenges for solid waste management is insufficient organization so that waste is piling up at the source. In addition there are other challenges for small companies, like pay delay of customers, the high cost of the operations, poor infrastructure, harassment by NCC, high costs of operation licenses, 
obstacles to recycling and the insecurity of the dump site. Then there is lack of protective gear as well as equipment and limited space.

The students came up with some suggestions for a start-up company. Their advisory business plan proposed to start on a small scale, not to buy land and to sort the waste in the truck by which it is collected. To that end a truck should be bought (cheaper than hiring) and besides the manager and the driver two sorters should be hired. With a number of 85 residential and commercial clients such a company would be able to realize a modest positive revenue. Included in their final advice was a small amount of payment to the street boys in the neighborhood in order to prevent the truck from being damaged and also such provisions as buying not worn out but secondhand tires for the truck, because that would be less expensive and more reliable than buying new ones, of which the quality is not guaranteed.

\subsection{The Case of Wind Energy}

The main focus of this project carried out in Nanyuki region, was on transferring Western-based knowledge to Kenyan stakeholders so that SWT (Small Wind Turbine) activities would continue after departure of the Western internship students (Buntsma \& Fugers, 2009). The NGO where the students worked, was interested in a working wind turbine for own usage, but was not eager to learn about the technology itself. The student groups succeeded in collaborating with a local welder (popularly referred to as Jua Kali, Artisans) from Naro Moru to manufacture a small wind turbine. Despite the rather straightforward technology and the welder's enthusiasm to cooperate, it took some effort for the welder to build a small wind turbine all by himself. The reason was not only that the technology was new, but also his lack of confidence and a dependent attitude towards what he considered as the experts. For example, in the beginning, the welder was over-reliant on the students' opinion and lacked initiative, despite the students' efforts to support rather than control the welder in the SWT manufacturing. Furthermore, once the welder had succeeded in building an SWT with little external help, he handed in a project proposal to NGOs for generating funds for continuing his SWT activities instead of approaching a bank for a loan. So much was it out of his scope to implement the technology in a businesslike way.

Although the primary determinant for sector growth is entrepreneurship (Samli, 2009), only a few retailers are actively selling imported SWTs, and only recently a second local SWT manufacturer has entered the market. This lack of entrepreneurial activities has its reasons. For many years political uncertainty and corruption were the main obstacles for individuals to engage in, or start a new business. Bribery was a common practice, and only those with good political connections were able to successfully venture into business. For example, tenders did not go to the best proposals, but to the one which was part of the right circle or patrimonial system. Since the demise of the Kanu regime in 2002 and especially after the promulgation of the new constitution of 2009, corruption has significantly reduced. However, fraud is 
still ingrained in the Kenyan society, and still commonly occurs in both the public and private sector. Furthermore, despite these improvements, the government still has a bad reputation regarding corruption. In particular, the removal of the immediate director of Kenya Anticorruption Authority (KACA), P.L.O. Lumumba and his deputies, is seen as a case of corruption fighting back. Still, people do not trust the government, and would rather avoid government officials than work with them.

A practical manifestation of this attitude is the attempt by one of the interns to get market information and wind data from the government, which are two crucial pieces of information required to carry out SWT experiments or start a business. Unfortunately, she could not access such data because she was required to pay for it. Such a policy puts obstacles in the way for the promotion of wind energy instead of supporting it. Later a government official confirmed that actually such wind data are supposed to be available for free, which apparently confirms that existing practices do not meet the standards of official policies. Furthermore, universities and companies, which are, or have been, involved in small wind turbines all have collected their own wind data sets and have fragmented market knowledge. This information is not shared amongst the industry players and the individual actors are left with insufficient data to develop appropriate products or successfully commercialize them. Even though the SWT companies also lack financial resources to set up a public awareness campaign, they have not marshaled forces for launching anything like that.

As previously mentioned, the high upfront investment is a key barrier for end-users to purchase a small wind turbine. The majority of the financial institutions have unfortunately been reluctant to support the purchase of SWTs, since there is lack of awareness of the technology and the business opportunities of energy products in general are not recognized. Consequently, no appropriate financing mechanisms for SWTs have been developed so far.

Generally, there are hardly any linkages between the different Kenyan SWT actors; and there is no common knowledge or database on the SWT technology and user experiences. Thus every time a new actor initiates an SWT experiment, he or she is starting from scratch instead of building upon gained experiences.

\subsection{The case of Solar Energy}

Another internship student, Max Tack, conducted a master thesis study in Kenya on the implementation of solar energy technology and the impact of cultural characteristics on that (Tack, 2010). He did an internship at Sunrays Solar, a mediumsized solar energy technology company in Kenya, and conducted many expert interviews, concentrating on the creation of stakeholder networks. This is difficult in Kenya because of a general lack of cooperation and a climate of selective trust, whereby one can only invest in a selected few that one knows all too well. He connected his analysis and findings to theories on culture from Hofstede (1997) and Trompenaars (1999). 
Specific cultural characteristics, which have a long tradition in tribal Africa, may explain the situation. In the first place there is a strong collectivist attitude, which means, that generally people are part of closed 'we' groups. This can be the tribe or clan, or a patronage or clientele system, but also a company or a governmental organization, or even an NGO. There is competition, but no cooperation. The consequence of this attitude is that competing companies do not cooperate in efforts to enlarge the market, say, by organizing an advertisement campaign together. In addition there is no cooperation within the sector, to put in place regulations and agreements in order to maintain the quality of the products. On the contrary, the recently founded sectoral solar energy organization has set high fees for membership, thereby making it difficult for new companies to enter the market. Lack of regulation also makes it easy for 'crook companies' to spoil the market by selling bad products, which lay idle after a while. This is detrimental to the reputation of solar energy in general, because the technology itself gets blamed instead of the bad organization and management.

Secondly, in Kenya there is strong particularism, which means that generally not rules but relationships are important and, therefore, affective relationships, likes and dislikes, preclude neutral and role dependent behavior. People of high status, or of the same group, or simply people who know and trust each other, receive a preferential treatment. This also affects the regulatory body of the government, which has been called into being recently. It is important to have access to high status government officials, in order to keep the company going, because it is easy for the bureaucracy to create obstacles for companies, for instance, by postponing their license, or simply delaying some important papers for the operation of the company. This means that some big players, who are well connected to politicians, actually control the market. Customers too find their way to companies via personal relationships. They do not trust a company, but they trust a person. If this person moves to another company, his customers will follow suit. There is no anonymous trust like one can expect in a situation where everybody plays by the rules, and treats everybody on an equal footing.

Thirdly, status usually is derived from the position within a company or group, not by achievement or by labor. Usually this also means that employees work on their status within the group and their relation with the boss more than concentrating on performance and on work and labor. Not much attention is given to maintain good relationships with the users.

In the fourth place, sequential dealing with time, i.e., planning and looking forward, is not strongly developed. From their side users too do not bother about a maintenance contract. Of course it costs money and hopefully future days will take care of future problems. Apart from lack of cooperation and of networking between users and companies, there is also lack of cooperation with knowledge institutes. There is strong traditionalism which means that things remain as they are and as a consequence, even if there are problems, nobody takes the initiative and everybody is inclined to remain 
waiting. People recognize that there would be much benefit in having knowledge institutes, like universities, involved in the development of solar energy, if asked. But they are inclined to wait for the other party to start.

Traditionalism and fatalism, to accept things like they are, like rain and sunshine, are closely connected. These attitudes are part of a collectivist mindset that prevents people from going against the group and start something new. Creativity means loneliness, but also initiative. In this regard, another cultural characteristic is involved, i.e., uncertainty avoidance. Facing uncertainty of course means to face an unknown future and often implies to go a lonely way forward into novelty. Generally, people are inclined to avoid situations they do not know for certain how to deal with, lest one does something wrong. Generally, the cultural characteristics summarized here, and described by our master student in his interview reports, are typical of closed in-group societies like tribal and agrarian societies, not to open markets and to open civil society oriented societies (Kasfir, 1998).

\section{Conclusion}

The state of affairs, described above, leads to a situation in which it is difficult to implement sustainable technologies, because an important first step, network formation, is slow. This has its origin in the compartmentalization of the Kenyan civil society: companies, government bodies, NGOs - often - are not very accessible to each other and tend to maintain a culture of closed "we" groups. This prevents learning experiences to take their course, and finally it does not stimulate the growth of expectations. It is to be mentioned, however, that a continuous struggle is going on to create a more open society, open cooperation and anonymous trust, regulated by law and rules, involving a culture of egalitarian relationships and personal initiative. This is happening both at the national level and at the societal level; and it is reflected in many projects and partnerships. Kenyan society is moving in the direction of modernity and in this process modern technology and modern organizations play a key role.

In general, Sub-Saharan Africa appears to be caught up between two competing sets of cultural values and institutions: a set of small-scale oriented values and institutions derived from its tribal and collectivist past, which do not function anymore in a time, where large-scale politics and technology creates one system of socio-economic interaction; and a set of large-scale civil society oriented values and institutions, like free association of individuals, universalistic rule of law, checks and balances on governance, an entrepreneurial spirit etc., which is not fully functioning yet.

The challenge lying before us is to integrate technology and policy transfer into a strategy for cultural transition, in which an equilibrium and also a courageous step forward is taken by a creative combination of old and new values and policy approaches. Africa has to face a conscious cultural transition from a tribal/hierarchical clientelistic society, with selective trust towards a stable government and a strong and 
open civil society (Popper, 1965). Such a society is characterized by pluralistic cooperation, and competition of many stakeholders; based on anonymous trust and judicial checks and balances. This cultural transition should be explicitly part of the development agenda, and be conducted in a path dependent way: preserving valuable parts from the past, but courageously entering upon a new socio-political and economic dispensation. This can address the issues of poor investment, skewed distribution of available resources, underproduction of civil servants and poor exploitation of natural resources, surfacing corruption and grinding poverty, among many other challenges. Entrepreneurial initiatives from below and consistent regulation from above together with multiple coalitions within all layers of society may create a flourishing civil society and a growing economy.

\section{References}

Alberts, A., Van Huijstee, J., Vogel, M., (2010), Business Plan AFRIWAC: Solid Waste Management in Nairobi, students internship report TU Delft.

Buntsma, J., \& Fugers, B. (2009). A Small Wind Turbine Business in Kenya. Delft University of Technology, Delft.

Calderisi, R., (2006), The Trouble with Africa: Why Foreign Aid Isn't Working, Yale University Press

Chang, H.J., (2007), Bad Samaritans - the Guilty Secrets of Rich Nations and the Threat to Global Prosperity, Random House, London

Collier, P., (2007), The bottom billion: Why the poorest countries are failing and what can be done about it, Oxford University press, New York

Easterly, William, (2006) The White man's burden: why the West's efforts to aid the rest have done so much ill and so little good, Penguin books, New York.

Des Gasper, (2004), The Ethics of Development, Edinburg: Edinburg University Press

Gyekye, K., (1997). Tradition and Modernity: Philosophical Reflections on the African Experience, Oxford University Press, New York

Hofstede, Geert (1997): Cultures and Organizations; Software of the Mind, Mc Graw Hill, New York.

Jacobsen, S., Bergek, A., (2006), A Framework for Guiding Policymakers Intervening in the Emerging Innovation Systems in 'Catching up 'Countries, in The European Journal of Development Research, Vol. 18, No. 14, December 2006, pp. 687-707

Kasfir, N. (1998), Civil Society and Democracy in Africa, Critical Perspectives, Routledge, New York

Kroesen, O and Rozendaal, A., (2010), A Cross-Cultural Management System : The Ubuntu Company as Paradigm, Int. J. Technology, Policy and Management, Vol. 10 no. 3 pp. 284298 
Moyo, D., (2009), Dead aid, why aid is not working and how there is another way for Africa, Penguin Books, London

Museveni, Y.K., (1996). Science and Technology as a Solution to Africa's Underdevelopment. In T. Abdul-Raheem (ed). Pan Africanism: Politics, Economy and Social Change in the Twenty-First Century. London: Pluto Press

Nyasani, J.M., (2010). Philosophy of Development: African Perspective - Reflection on why Africa May Never Develop on the Western Model. Nairobi: Consolata Institute of Philosophy

OSSREA (Organization for Social Science Research in Eastern and Southern Africa), (2009), Good Governance and Civil Society Participation in Africa, Addis Ababa, Ethiopia

Popper, K.R., (1965). The Open Society and Its Enemies. London: Hutchinson,; Fukuyama, F., (2011). The Origins of Political Order. London: Exmouth House.

Prahalad, C.K., and Hart, S.K., (2002), The fortune at the bottom of the pyramid, Strategic Business, 26.

Reader, J., (1997), Africa : a Biography of the Continent, Penguin, London

Sachs, J.D., (2005), The End of Poverty: How we can Make it Happen in our Lifetime, New York, Penguin Books

Samli, A.C., (2009), International Entrepreneurship, Innovative Solutions for a Fragile Planet, Springer, New York

Schouten, T. and Moriarty, P., (2003), Community water, community management. From system to service in rural areas, IRC, London

Sen, A., (1999), Development As Freedom, Anchor Books, New York

Tack, M., (2010), Actor Network Development in Strategic Niche Management; Analysis in the field of Solar Energy in Kenya, Master Thesis, TUDelft.

Trompenaars, F, and Hampden-Turner, C., (1999) Riding the Waves of Culture, London, Brealey

Veen, R. van der, (2004), What Went Wrong With Africa: A Contemporary History. Amsterdam: KIT Publishers

Wiarda, Howard J., (2003): Civil Society -- the American model and third world development, University of Massachusetts 